\title{
Delicate Natural Emotion - Japanese Design Culture Reflected through Ryohei Kojima
}

\author{
Xiao Cai \& Baiyang Jin \\ College of Art and Appareluages \\ Tianjin Polytechnic University \\ Tianjin 300160, China \\ E-mail: aybug@126.com
}

\begin{abstract}
This paper aims to explore the influence of culture over design. Plain design is a means for visual communication, however, it does not just convey information, but also needs to introduce more people and events. To put it in other words, plain design aims to arouse the resonance of its targeted groups so as to move people's heart. The creation of a designer is, to great extent, influenced by his or her national or regional culture.
\end{abstract}

Keywords: Japan culture, Ryohei Kojima, Delicate, Natural

\section{The realistic meanings of the study on Japanese design culture}

This paper aims to explore Japan culture in a gentle, straight and exquisite means and to study a nation's culture through studying the internal nature of master's works. At a time where the public opinions are at large sharpened and post-modernism is popular, "to focus on behind-the-surface" conduces to the communication of national culture.

Modern design tends to more and more recognize localized and national character. As a matter of fact, with the globalization and the integration of systems, localization becomes more and more important in providing power for preserving the meanings of objects' existence. Localization is to recognize local culture rather than to recognize symbols or graphs. To explore the connotation of local culture, to find out the conflicting points between traditional culture and individual personality, and to form individual design style is the soul of design's localization. The success of Japanese design is the success for Japanese to imbed eastern concepts into their design works. Although we could find in Yamato culture traits left by China's culture, the "returning" feature of eastern culture shown in design works by Japanese designers is better than that by Chinese designers.

\section{Introduction of Ryohei Kojima and study on his works}

Plain design is a means for visual communication, however, it does not just convey information, but also needs to introduce more people and events. To put it in other words, plain design aims to arouse the resonance of its targeted groups so as to move people's heart. Therefore, designers should focus on creating works through special a unique methods so as to make works viewers happy. The creation of designers is, to great extent, influenced by their national or regional culture.

\subsection{Introduction of Ryohei Kojima}

Ryohei Kojima is a famous contemporary Japanese designer. His works are mainly plain posters and at mean time, he also designed many successful commercial works.

Life introduction:

1939, born in Kamaishi, Japan

1959, graduated from Asagaya Art School

1961, graduated from Mashashino Art University, majoring in Commercial Design

1963, worked in Sunshine Advertisement Company

1975, established Ryohei Kojima Design Firm 
1965, won JAAC Special Award and Tokyo ADC Silver Award

1972, 1973, 19741975 and 1977, won Sun Advertisement Award

1978, won Japan Advertisement Design Silver Award

1981, won Japan Advertisement Design Golden Award

1980, won Japan Everyday Advertisement Design Best Award

1988, Japan News Association News Advertisement Award

1991, New York ADC Excellence Award

His "environment" poster is collected by Victoria Museum and Albert Museum. He is the member of Tokyo ADC, Japan JAGDA, and New York ADC.

\subsection{Study on Ryohei Kojima's works}

In the plain design works by Ryohei Kojima, most are natural things and the subjects are mostly flowers, grass, trees, birds, insect, fish and other natural things. His works resemble Chinese traditional culture. He is good at symbolizing and simplifying his subjects. In his works, there are always healthy and plebeian aesthetic awareness, which is not encumbered by dashing decorations and has the sense of plain mark. The most successful point of Ryohei Kojima in shaping is that he uses the fewest shape elements to construct his shaping world. Actually, it is a world of black and white where colors are not the most important factors and colors are just an auxiliary means in the exploration process. Ryohei represents his thoughts through the comparison of geometrical shapes. However, he eventually leaves us with amiable colors and makes us happy. In graph treatment skills, to change the point to view the object is the most frequently method applied by him. He uses the methods of seeing objects from the back and seeing object's side across; he makes use of the relationship of the light facing and light back; he applies superposition, joining, separating, disorderly viewing, folding, knotting, and tying. He conducts shape treatment on objects in circle, square and triangles. What is more, he hides them behind the organic shapes. Another character is to transform by combining several geometrical graphs. The complex shape combination by Ryohei Kojima is like computer editing system. No matter what kind of objects, he could easily handle them.

\section{Ryohei Kojima and Japanese design culture}

\subsection{The realistic spirit in Japanese design}

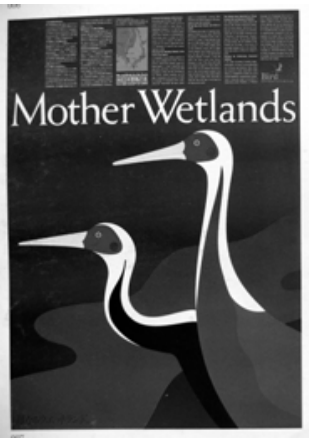

The design of Japan, no matter it is plain design or industrial design, is of the leading position in the world.

Japanese art may be simple or complex, serious or err, abstractive or realistic. It is the combination of eastern and western culture. In Japanese design works, we could see the spirit of quietness, emptiness, and void and could feel the eastern abstract.

Japanese is Yamato and Yamato is a people of deep suffering awareness. North European people consider design as a part of their life. Americans view design as the means for making money, while Japanese take design as the means for their nation's existence. Because Japan is an island country and is lack of natural resources, to export electrical equipments becomes an important economy resource for Japanese. Therefore, the design directly relates to the economy lifeline of their country. Hence, Japanese design even draws their government's attention. Japanese design starts from 1950s. Their nation's personality makes their design very strong. Japanese is the best

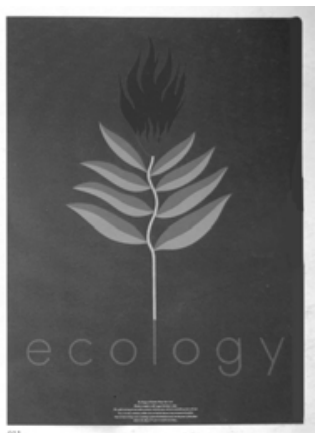
student in the world. They could widely learn foreign valued knowledge and to use them in practice. At the same time, Japanese is good at teamwork, which enables the inner power of enterprises show in a focused way. Two elements in Japanese traditional help Japanese avoid mistakes. One is the simple style and the other is the modulus system with Tatami as the standard, which enables them to rapidly accept the modulus concept introduced from Germany. The narrow space makes Japanese like small, standard and multi-functional products, which complies with international market needs. Hence Japanese electrical equipments lead world fashion and are popular all over the world.

Internationalist style products can be produced in quantity and they are of low price and are suitable for the general public needs. It is only in the design process that sacrifices national character, local character and individual character to pursue common nature. Now, it is a transitional stage from industrialization to information technology. From the long-term interests, the product must have a personality if wants to have a place in the intense market competition. In design, it is a trend to, from the actual situation of countries and regions, combine national aesthetic mood with modern design factors that combine to form a unique design system. In this regard, the Japanese have done some useful exploration. 
At the same time, Japan's industrial design has gone through so complete development is because, first and foremost, the industrial design community in Japan attaches great importance to practice. The entire design community is closely connected with corporate sector. The vast majority of large-scale enterprises (large-scale enterprises in Japan accounted for about five percent) have huge product development department. In the industrial design, they invest a lot of money. Again, the Japanese design community is linked with social development. Japan Industrial Design Association's design direction, from the very beginning, starts from national situation. Social life changes can immediately get the attention from designers and the designers will explore the issue and form theory. The designers start from their nation's features, focus on the world needs, rather than just parrot. By this way, they could design good products that truly meet the needs of their national people, which have their own characteristics and can also meet the world needs.

\subsection{The delicate nature in Japanese design}

Japan's national sentiment should be very delicate. From literatures such as The Tale of Genji and Makuranososhi, we can see the foundation of Japanese culture, which is the sentimental aesthetic emotion and delicate spirit nature. When the fall comes, there will be food and refreshments called "Autumn Collection". "Autumn wind blows, tree leaves fall, mushrooms grow, trees bear fruits, wind blows the leaves to piles and piles". Japanese view such landscapes as beautiful, unlike the incomplete beauty in the eyes of Westerners. It is the care on the passing things. People focus on the emotional association rather than the objects themselves. Objects that are garbage in the eyes of Westerners, such as the leaves and nuts, the Japanese put them into chestnuts, gingko, mushrooms, and beautifully decorate them together. Such sense of beauty is Japan's unique aesthetic beauty. It is not continental culture. We need to re-examine this new awareness of beauty. Because Japanese culture is too emotional and is lack of theoretical system,

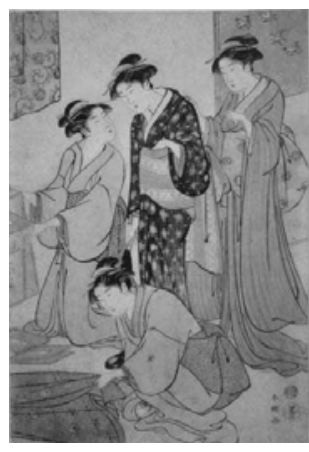
it is hard to develop into a doctrine or faction. Now the doctrines in Japan, such as impressionist art, abstract, the new realism, are all imported from foreign countries. Japan lacks for the capacity to develop their ideas generated in the country into a system.

For Japanese, to say pure art is no better to say to make design closer to people's life. At the beginning of Jianghu period, with the efforts of Guangyue, Zongda and Guanglin, there formed classis Japanese decoration style. To look carefully, the fan painting and folding screen painting all have organic characters. The cragginess created by Guangyue and Zongda fixed the original form of Japanese book press. To some extent, the paintings of Zongda are posters. These works not only has practice nature but also has decoration and beauty values.

Japanese have the aesthetic awareness to think and explain its elements. For example, when expressing objects, they are not rational but emotional and spiritual. What is more, they usually express them in indirect way. They do not clearly express their attitude but express them in circumbendibus way, which is closely related to eastern traditional culture connotation. For example, Chinese ancient poems usually adopt metaphor and borrowing. This is a connotation aesthetics which believes that the feeling of beauty could be felt in the expressing of opinions. The enterprise image of advertisement owners could only win consumers' support when the express method is gentle and indirect. As visual expression method, it is also used in ancient Japanese paintings and water and ink paintings. It needs people to feel beauty in unclear and blurry state.

\subsection{The cultural origin of Ryohei Kojima's works}

Ryohei Kojima made many posters to introduce Japanese design style and Japanese culture. However, he would also think of how many unique national cultures are expressed in his works. Sometimes, we would think whether the Japanese styles in these works are formed from his unique design methods or from the eastern natural subjects used in these works or from the Japanese style coloring and patterns. To view culture as legacy is the consumption on the past culture.

From international point of view, we do not search for eastern emotion anymore. Therefore, Ryohei wishes not to use traditional and classic views to explore the inherent sense and culture owned by Japanese. In addition, another element is very interesting, that is, the tender thanks emotion provided by nature. When describing Japanese emotion, we usually use the words "Tuo and "Ji". "Tuo"means dreariness and "Ji" means loneliness. However, it is hard to understand if as an international concept. This is problem faced by eastern culture. To put it simple, in the traditional Japanese life, they like stones with lichenous better than bright marbles, and like naïve soil wall better than exquisite wall paper. If we just explain is as the thinking over nature, it is not enough. We may explain it as that compared with things that exist for ever, we could feel deeper beauty and love in the state where a object disappear gradually. This is the base for understanding and mastering the aesthetic awareness of Japanese.

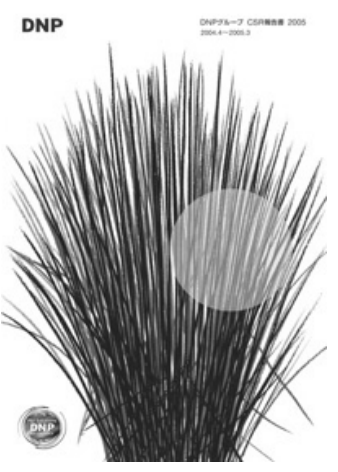




\section{The mater's design legacy - from nature}

Traditional Chinese painters consider the blank part in a picture as the base for people's imagination. Chinese philosophy advocates the movement of objects. In the process of searching for this point, we feel amiable when seeing Japan's design works. We know that we find sensitive and rational works. Ancient Japan advocates nature. About one thousand ago, Japan borrows culture, including Buddhism, Chinese writing system and the art and architecture of Tang Dynasty of China.

In Ryohei Kojima's works, he expresses the "black and white" theory in China's traditional artistic method with shapes and colors. Shapes play the main part and colors the auxiliary. No shape, no color. The connotation of Ryohei complies with the most basic aesthetic needs of people, that is, simplicity and purity is beauty. When bringing natural shapes into his works, he preserves the most original life power completely. Sometimes, he does not make any decoration. In his eyes, nature is perfect and what human beings could do is just to abstract.

The thought of Ryohei is an enlightening to the simple beauty in modern design.

Not only Ryohei Kojima advocated simple beauty, many other Japanese design masters also do so. One design master points out that, "there should not be any superabundance in design", from which we could know that his design concept is similar to the concept of "most appropriate" advocated by China's traditional aesthetics.

Japanese design applies natural and traditional concepts, modern elements and construction methods and is leading design in the world, which is worthy for Chinese designers to learn and refer to.

\section{References}

Benedict, Ruth. The Chrysanthemum and the Sword - the Patterns of Japan Culture. Beijing: Commercial Press.

Nathan, John. Japan Unbound. Huadong Normal University Press.

Wang, Shouzhi. World Modern Design History. New Century Press.

Wang, Shouzhi. World Modern Plan Design History. New Century Press.

Yi, Dingbang. Design Introduction. Changsha: Hunan Science and Technology Press.

Yuan, Yanzhai. Design in Design. Jinan: Shandong People's Press. 